Doi: $\underline{10.15863 / \mathrm{TAS}}$

\section{International Scientific Journal}

\section{Theoretical \& Applied Science}

p-ISSN: 2308-4944 (print) e-ISSN: 2409-0085 (online)

Year: $2015 \quad$ Issue: $01 \quad$ Volume: 21

Published: 30.01 .2015 http://www.T-Science.org

SECTION 3. Nanotechnology. Physics.
Ali Abid Abojassim

Assitance professor Ph.d. in Baghdad university, Faculty of Science. Department of Physic

University of Kufa, Iraq ali.alhameedawi@uokufa.edu.iq

Hussain H. Al-Gasaly Assitance professor Ph.d. in Mosco university, Faculty of Science. Department of Physic University of Kufa, Iraq halgazaly@yahoo.com

Faeq Abealluh AL-Temimie Ms.c. in Kufa university, Faculty of Science. Department of Physic University of Kufa, Iraq faeqa.jasim@uokufa.edu.iq

Muntathar A. Al-Aarajy Faculty of Science. Department of Physic University of Kufa, Iraq

\title{
STUDY OF TIME MEASURED FACTOR ON MEASURING RADON CONCENTRATIONS IN GROUNDWATER
}

Abstract: Radon concentration measurements were performed in all 24 samples of ground water at four locations in Al-Haidariya hand in Najaf, Iraq, using active RAD-7 continual radon measuring instruments. The radon concentrations were measured at different time $(0,24,48,72,96$ and 120) hour for determining daily correction factor in groundwater samples using the least-squares fitting method.

The experimental results show that the radon concentration at low and high time of measuring for all location

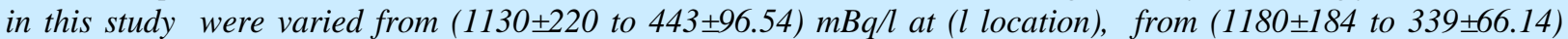

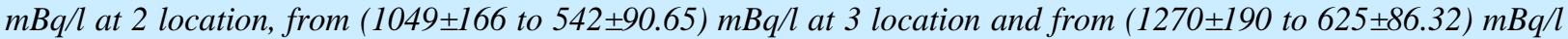
at 4 location, therefore the radon concentration increased with decrease time of measuring samples. The main finding of the least-squares fitting method investigation is that use present study, experimentally observed, the radon concentration can be determined theoretically by depending on the semprical formula which it was determined at different location.

This study proved that can be determined radon concentrations in water using RAD-7 detector at any day of measurement depending on the daily correction. Najaf.

Key words: RAD-7, Daily correction factor, Radon concentration in groundwater and Al-Haidariya hand in

Language: English

Citation: Abojassim AA, Al-Gasaly HH, AL-Temimie FA, Al-Aarajy MA (2015) STUDY OF TIME MEASURED FACTOR ON MEASURING RADON CONCENTRATIONS IN GROUNDWATER. ISJ Theoretical \& Applied Science 01 (21): 16-21. doi: http://dx.doi.org/10.15863/TAS.2015.01.21.3

\section{Introduction:}

Radon is a naturally occurring, colorless, odorless gas that is soluble in water. It is radioactive, which means that it breaks down to form other elements. The rate of radon's radioactive decay is defined by its half-life, which is the time required for one half of any amount of the element to break down. The half-life of radon is 3.8 days[1] . The source of radon is the radioactive decay of uranium. Therefore, higher radon amounts are commonly detected in areas underlain by granites and similar rocks that usually contain more uranium than do other rock types[2] . Radon moves from its source in rocks and soils through voids and fractures. It can enter buildings as a gas through foundation cracks or dissolve in the ground water and be carried to watersupply wells.

Radon-222 concentrations in ground water vary because of variable concentrations of sources in the aquifer materials, emanation rates from mineral sources, aquifer porosity, and permeability.

There are some scientists modernly using RAD7 detector to measure radon concentrations in groundwater[3-6].

The aim of the present work, radon concentration were measured in four a location of 
Al-Haidariya hand in Najaf, Iraq at different time $(0,24,48,72,98$ and 120 hour) using RAD-7 detector. Also study of effected time measurement on radon concentration using the least-squares fitting method and applied to find the parameters necessary to estimate radon at any time of measurement.

\section{Study Area}

Najaf is a holy city in Iraq. Najaf is located in southern Iraq near the historic city of Kufa, it is the capital of the province of Najaf. Najaf is away from
Baghdad about $160 \mathrm{~km}$ in southern direction and away from Karbala about $80 \mathrm{~km}$. in the direction of the north west. There are one of the hands in AlNajaf city Al-Haidariya. Al-Haidariya hand in An Najaf (region) is a town in Iraq - about $82 \mathrm{mi}$ (or 132 $\mathrm{km}$ ) South of Baghdad, the country's capital city. Its center lies at a latitude of 32.1520200 and longitude of $44.4014200 \mathrm{and}$ it has an elevation of 22 meters above sea level. Figure (1) shows the area of study which it is selected the region under study[7-9].

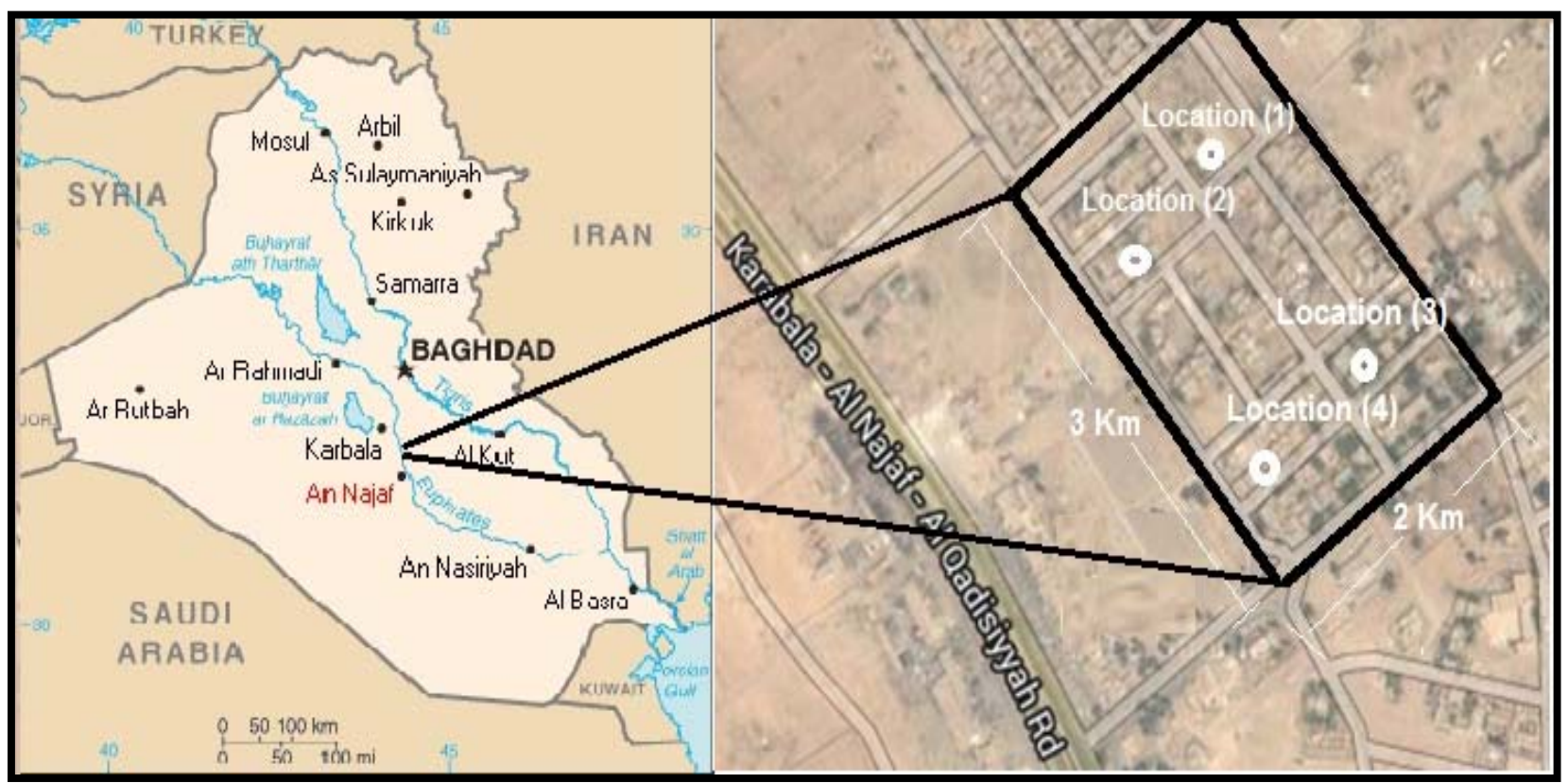

Figure 1 - Map of Al-Haidariya hand.

\section{Material and Method}

Location and Collection of the Samples

In the present study (4) location were chosen as fair distribution in Al-Haidariya hand in Najaf, Iraq. The methods which were used to collect the sample is described as follow: Five samples of groundwater are taken for each location at depth about over $10 \mathrm{~m}$ and for five time measurement over one week. The samples were kept in plastic container of volume 250 $\mathrm{ml}$. These were measured at location with a portable RAD-7 detector.

\section{Experimental Setup}

In the interior of the measurement instrument RAD-7 (from Durridge) is a hemisphere with a silicon solid-state detector. The $\mathrm{RAD} \mathrm{H}_{2} \mathrm{O}$ is an accessory to the RAD-7 detector that enables the measurement radon in water over a concentration range from less than $30 \mathrm{pCi} / \mathrm{L}$ to greater than $105 \mathrm{pCi} / \mathrm{L}$. The lower limit of detection is less than 10 $\mathrm{pCi} / \mathrm{L}$. The equipment is portable and battery operated, and the measurement is fast. An accurate reading of radon in water within an hour of taking the sample can be read. The RAD $\mathrm{H}_{2} \mathrm{O}$ gives results after 30 minutes analysis with a sensitivity that matches or exceeds that of liquid scintillation methods. The setup consists of three components, the RAD-7, on the left, the water vial with aerator. During the five minutes of aeration, more than $95 \%$ of the available radon is removed from the water. Fig. (1) shows the RAD-7- $\mathrm{H}_{2} \mathrm{O}$ schematic . 


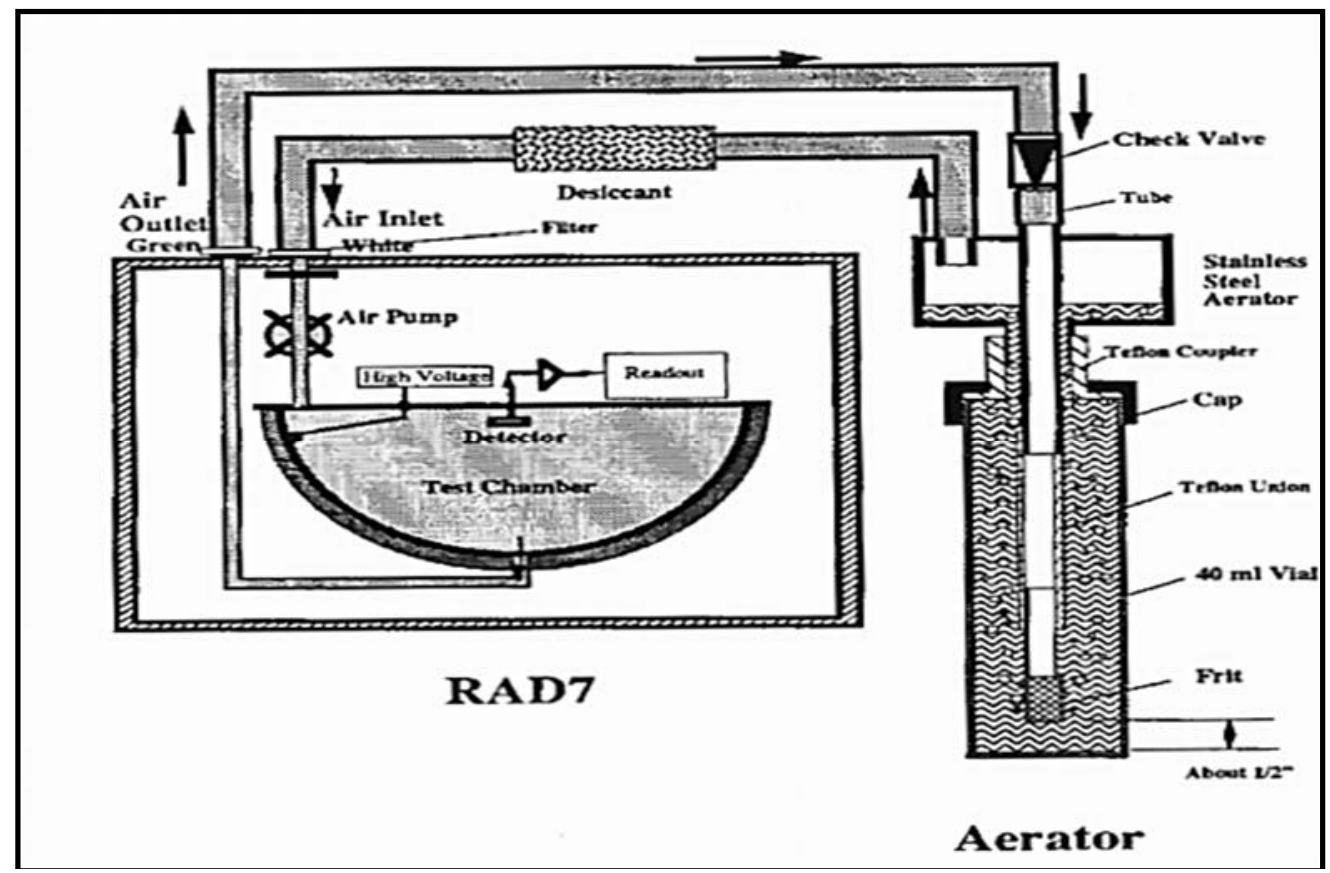

Figure 2 - Schematic diagram RAD-7- $\mathrm{H}_{2} \mathrm{O}$ assembly [10].

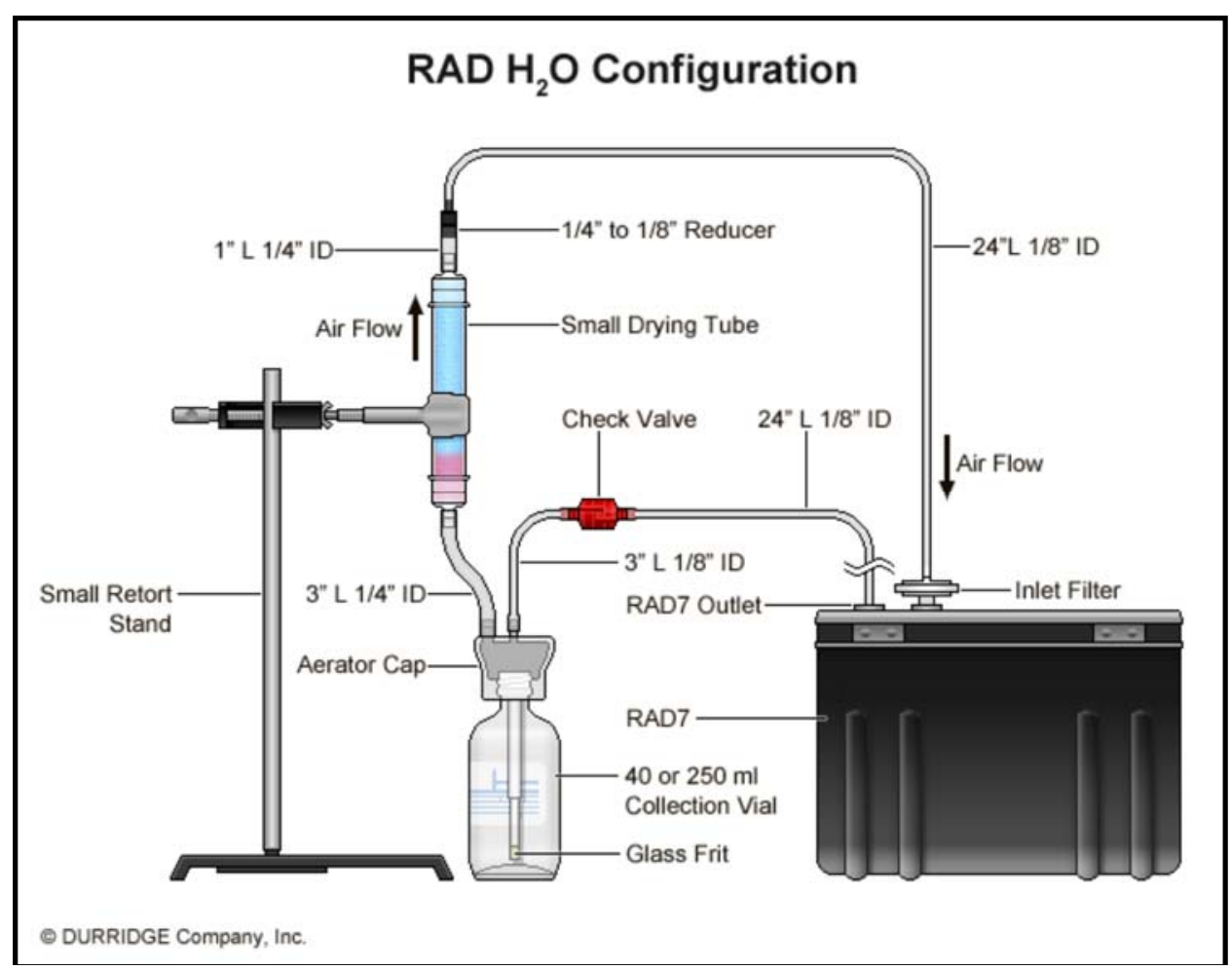

Figure 3 - Experimental laboratory set-up for Radon-in-water activity concentration measurements with Radon-in-air analyzer RAD7 plus the RADH2O accessory. Courtesy by Durridge, Inc. [11].

Theory of the least-squares fitting

The least-squares fitting are distinctive in the way that the solution is interpreted. the least-squares fitting problems usually incorporate some assumptions about the errors in the model. In this study the function is not linear because the radon gas decay as exponential carve so we using the nonlinear least-squares formulation method by math lab simulation program. The nonlinear least-squares formulation to fit a nonlinear model to data. This 
method is defined as an equation that is nonlinear in the coefficients where the nonlinear models are more difficult to fit than linear models because the coefficients cannot be estimated using simple matrix techniques. This method is known as the method of least squares because the idea is to make the squares of the errors as small as possible. It is a method very widely used in statistics[12-14].

Result and Discussion:

Table (1) show the experimental results of average of radon concentration for unit $(\mathrm{mBq} / \mathrm{l})$ of ground water in four locations of Al-Haidariya hand in Najaf in different times $(0,24,48,72,96$ and $120)$ hour. Table (2) show the theoretical value of the radon concentrations in sample of groundwater at same time measured $(0,24,48,72,96$ and 120 hour) that it are calculated using the least-squares fitting method.
From Table (1) for all samples were found that the maximum value of radon concentration for all samples at different time measured is lower than the recorded values of radon concentration in groundwater which it is the safe limit of $11 \mathrm{~Bq} / 1$ recommended by the US Environmental Protection Agency (USEPA)[15]. Also from Table (1), Table (2) and Figure (2), we are found that the radon concentration decreasing with increasing time measured. The reason for decreasing in radon concentration duo to the relation between radon concentration with time measured is decayed, therefore may be found the semprical formula (determined by the least-squares fitting) depending on experimental and theoretical results as the bellow equations:

Radon Concentrations $($ Exp. $)\left(\frac{m B q}{l}\right)=1167.1 e^{-0.007 \times \text { Time Measured }}$
Radon Concentrations (Theo. $)\left(\frac{m B q}{l}\right)=1155.5 e^{-0.007 \times \text { Time Measured }}$

From equations (1) and (2), we found that must factor be added the correction when it is measured Radon concentrations in water samples by RAD-7 detector at different times measured. Because the half- life of radon gas is 3.8 day and take samples in glass duo to escape of radon from the water sample.

Experimental results of Radon concentrations in groundwater in Al-Haidariya Hand.

Table 1

\begin{tabular}{|c|c|c|c|c|c|}
\hline \multirow{2}{*}{ Time (hour) } & \multicolumn{5}{|c|}{ Average of Radon Concentrations in (mBq/l) } \\
\cline { 2 - 6 } & Location 1 & Location 2 & Location 3 & Location 4 & Mean \\
\hline 0 & $1130 \pm 210.230$ & $1180 \pm 207.001$ & $1049 \pm 185.771$ & $1270 \pm 189.076$ & $1157.25 \pm 92.889$ \\
\hline 24 & $953 \pm 135.657$ & $964 \pm 123.322$ & $914 \pm 124.453$ & $1102 \pm 125.448$ & $983.25 \pm 87.175$ \\
\hline 48 & $792 \pm 101.765$ & $770 \pm 90.078$ & $807 \pm 106.670$ & $960 \pm 110.980$ & $832.25 \pm 98.869$ \\
\hline 72 & $667 \pm 98.980$ & $587 \pm 84.879$ & $712 \pm 92.098$ & $832 \pm 89.903$ & $699.5 \pm 110.622$ \\
\hline 96 & $553 \pm 90.901$ & $4482 \pm 88.804$ & $625 \pm 92.306$ & $732 \pm 78.093$ & $588 \pm 117.913$ \\
\hline 120 & $443 \pm 87.412$ & $339 \pm 78.521$ & $542 \pm 88.706$ & $625 \pm 75.678$ & $487.25 \pm 120.648$ \\
\hline
\end{tabular}

Table 2

Theoretical results of Radon concentrations in groundwater in Al-Haidariya Hand.

\begin{tabular}{|c|c|c|c|c|c|}
\hline \multirow{2}{*}{ Time (hour) } & \multicolumn{5}{|c|}{ Average of Radon Concentrations in (mBq/I) } \\
\cline { 2 - 6 } & Location 1 & Location 2 & Location 3 & Location 4 & Mean \\
\hline 0 & 1136.74 & 1183.198 & 1046.848 & 1269.573 & 1159.09 \\
\hline 24 & 947.21 & 928.505 & 919.6 & 1104.597 & 974.978 \\
\hline 48 & 789.28 & 728.637 & 807.82 & 961.059 & 821.699 \\
\hline 72 & 657.68 & 571.792 & 709.627 & 836.174 & 693.818 \\
\hline 96 & 548.03 & 448.71 & 623.369 & 727.516 & 586.906 \\
\hline 120 & 456.65 & 352.121 & 547.597 & 632.978 & 497.337 \\
\hline
\end{tabular}




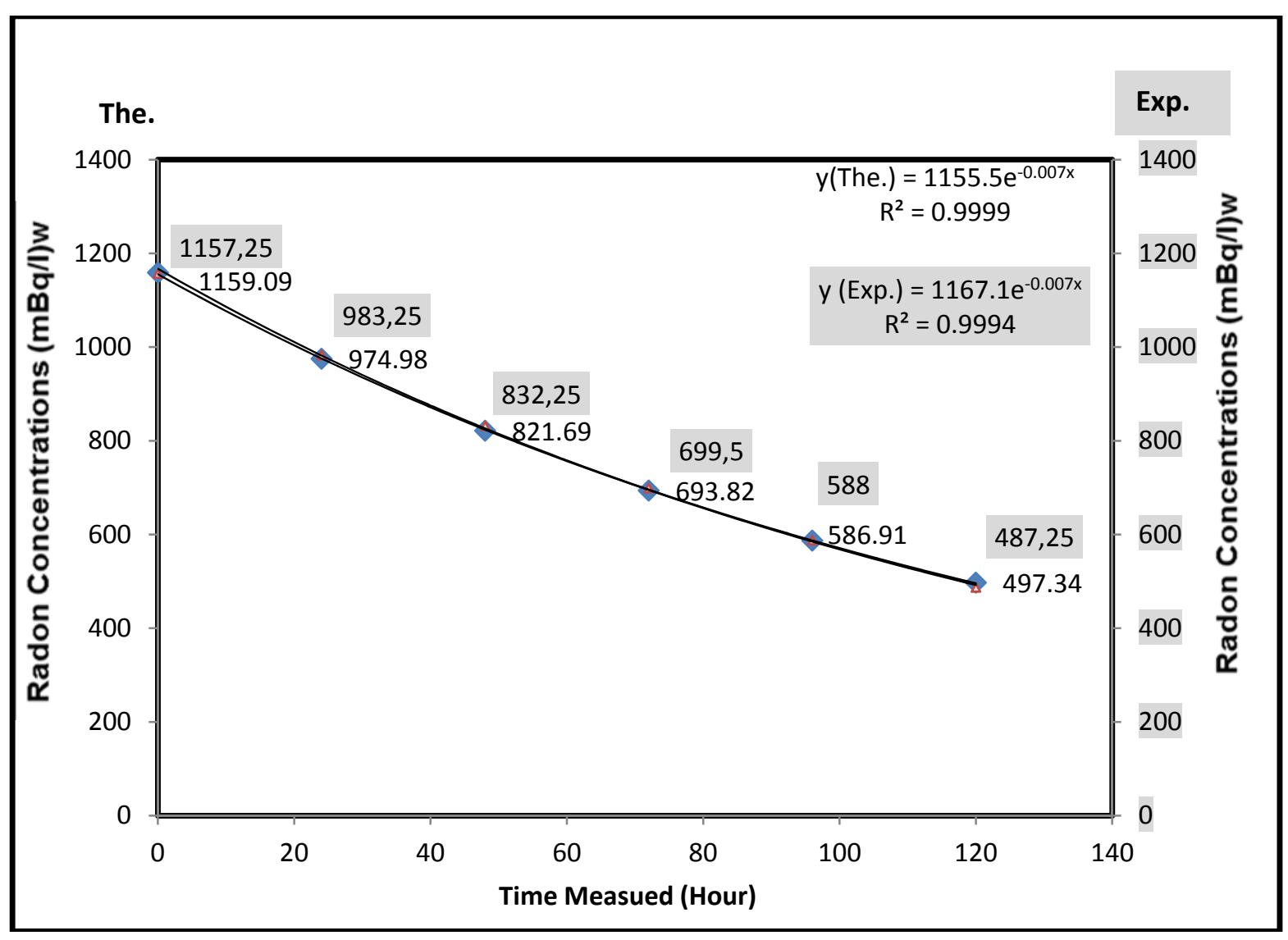

Figure (4) Relation between the average of Radon concentrations and time measured experimentally and theoretically.

From Figure (4), we found perfect agreement between experimental and theoretical method for radon concentrations in groundwater samples, therefore, we can be found the radon concentrations for any time measured by theoretical method if we determined only the radon concentration at zero of time measured.

\section{Conclusion:}

The Radon concentrations in natural ground water of Al-Haidariya hand in Najaf, Iraqi district the water samples were collected are measured by RAD-
7 technique at different times. All the Radon concentrations were observed that were well below the prescribed dose limit of the US Environmental Protection Agency (USEPA). The semprical formulas were found experimentaly and theoreticaly studies for determining the concentrations of Radon gas in groundwater at different time of measured. Also, we can be found the Radon concentrations for any time measured by theoretical method if we determined only the radon concentration at zero of time measured.

\section{References:}

1. Hem JD (1985) Study and interpretation of the chemical characteristics of natural water: U.S. Geological Survey Water-Supply Paper 2254, p.263.

2. Faure G (1986) Principles of isotope geology: New York, John Wiley and Sons, Inc., 589 p.

3. Surinder Singh, Arvind Kumar, Bikramjit Singh Bajwa, Sandeep Mahajan, Vinod Kumar and Sunil Dhar (2010) "Radon Monitoring in Soil Gas and Ground Water for Earthquake
Prediction Studies in North West Himalayas, India", Terr. Atmos. Ocean. Sci., Vol. 21, No. 4, 685-695, August 2010.

4. Ali A. Al-Hamadwi, Abdulhussan A. Al.Bayati and Asia H. Al.Mashhadani (2012) Radon and Thoron Concentration measurement of Ground Water in Kufa City by using RAD7 detector", J. of kufa- phy., Vol.4, No.2, 44-49,2012.

5. Ali A. Abojassim (2013) Radon Concentrations Measurement for Drinking 
Water in Kufa City /Iraq Using Active Detecting Method", Advances in Physics Theories and Applications, Vol. 26, 30-35, 2013.

6. Vikas Duggal, Rohit Mehra and Asha Rani (2013) Determination of ${ }^{222} \mathrm{Rn}$ levels in groundwater using RAD-7 detector in the bathinda district of Punjab,INDIA", Radiation Protection Dosimetry, Vol.18, 1-7, 2013

7. Jump up ${ }^{\wedge}$ Nakash, Yitzhak (2003) The Shi'is of Iraq. Princeton University Press. Retrieved 2009-09-13.

8. Jump up ${ }^{\wedge}$ Yitzhak Nakash (1994) The Shi'is of Iraq (Princeton: Princeton University Press, 1994) p. 16

9. Toynbee Arnold J (1935) Survey of International Affairs 1934. London: Oxford University Press. pp. 120-122.

10. (2012) DURRIDGE, RAD7 RADON DETECTOR. Owner's Manual (Bedford, MA.), 2012, USA.
11. (2012) DURRIDGE, RAD7 RADH20 Radon in Water Accessory. Owner's Manual (Bedford, MA.), 2012, USA.

12. K.Madsen, H.B. Nielsen and O. Tingleff (2006) Methodes for non-linear least squares problem", infomatics and mathematical modeling technical university of Denmark, 2nd Edition, non-linear time series", J. arxiv math. Phy. Vol.19, 2006.

13. M. Sari (2012) "An improved method of fitting experimental data to the Hoek-Brown failure criterion", Engineering Geology, No.127, pp.27-35.

14. (1991) United States Environmental Protection Agency (USEPA). Federal Register 40 Parts 141 and 142: national primary drinking water regulations; radionuclides: proposed rule. U.S. Government Printing Office. 